\title{
Experimental Investigation of Laminated Rubberized Aramid Armor Plates Resisting .30 Caliber Fragment Simulating Projectile Impact
}

\author{
Veysel ALANKAYA* \\ Department of Naval Architecture, Turkish Naval Academy, Tuzla, 34942 Istanbul, Turkey \\ cross $^{\text {ref }}$ http://dx.doi.org/10.5755/j01.ms.22.2.7682
}

Received 28 July 2014; accepted 25 January 2015

\begin{abstract}
Establishing the survivability for armed forces and police teams, attentive solutions are needed owing to the damage mechanism of fragments that have more kinetic energy than traditional bullets. Nevertheless, determining the damage capability of composite laminates against fragment impact at ballistic velocities is a challenging issue because of the difficulty in determining elastic stiffness of the armor due to the complex damage modes, which can occur in composites through impact phenomenon. Fire tests are generally considered to be the best validation method for procurement transactions of customers. This study presents the effects of impact velocities for rubberized aramid plates on the basis of computerized tomography scans taking into consideration composite failure modes. Additionally, the impact damage of plates at different ballistic velocities is presented, supported by real test reports focusing on the penetrating prevention capability and a predictive equation of ballistic limit velocity for rubberized aramid plates resisting. 30 caliber FSP is developed.

Keywords: body armor, laminated composite panel, ballistic damage, rubberized aramid.
\end{abstract}

\section{INTRODUCTION}

It is essential that operational needs be considered when the problem is designing a new armor. It is almost impossible to use high weighted armors for troops owing to the fact that high weight makes them slower and exhausted or body armor with shoulder and neck protection parts may prevent quick moves. Wambua [1] defines that use of ceramics for body armor due to the weight considerations has continued to decrease over years. Ceramics are, however, brittle and normally have to be backed by a laminate of high strength and high modulus. Correspondingly, armored vehicle designers try to balance vehicle "protection", "performance" and "payload" through an integrated survivability approach that starts with (i) Occupant and preferential components protection, (ii) Maneuverability performance consisting sustainable speed and (iii) Payload capability for operational requirements. This associated structure forces designers to use low weighted materials with sufficient properties.

Modern composites have created a revolution in lightweight armors both for personnel and vehicles. When compared to conventional materials, modern composites have superiority due to their high strength to weight and stiffness to weight ratios, resistance to environmental conditions, design flexibility also known as tailoring the material for desired application which make them attractive for a wide range of applications at different threat levels and environment $[1,2]$.

Textile composites which have high energy absorption and through the thickness strength and stiffness properties, have been commonly preferred for armor applications recently [3]. Glass fibers (S and R glass), aramid (Kevlar,

\footnotetext{
* Corresponding author. Tel.: +90 216395 2630-3363.

E-mail address:valankaya@dho.edu.tr (V. Alankaya)
}

Twaron) and high performance polyethylene (HPPE) fibers (Dyneema, Spectra) are introduced on the market for textile composites [4].

The analysis of composite materials brings additional difficulties such as the inter-laminar or transverse shear stress due to mismatch of material properties among layers, bending-stretching coupling due to asymmetry of lamination, and in-plane orthotropy. Additional complexities occur while composite material resists to the impact loads. The penetration and perforation of targets by projectiles involve highly complex processes, which could be analyzed through three basic approaches: (i) Empirical prediction models, which require lots of experimental tests and results, (ii) Prediction models, which require typical ballistic impact experimental data as input, (iii) Analytical models, which take only mechanical and fracture properties and geometry of the target and projectile parameters as input $[3,4]$.

Common analytical models considering energy and momentum changes during impact phenomenon and the effect of impactor nose shape are presented by Hetherington [5], Corbett et al. [6], Goldsmith [7] and Ben-Dor et al. [8,9]. Detailed explanations consisting of contact mechanics, structural dynamics, strength, damage mechanics with both analytical and experimental models about impact behavior of composite structures with the factors effecting ballistic limit velocity, are presented by Abrate [10] and Reid et al [11].

Wen $[12,13]$ presented the equations for the ballistic limit of projectiles with conical, flat, hemispherical and ogival nose shapes impacting to E-glass/Polyester, S2glass/Phenolic and E-glass/Phenolic composite plates. One of the recent researches focusing on the $3 \mathrm{D}$ woven composites and consisting modeling techniques along with their capabilities and limitations at impact behavior is presented by Ansar et al. [14]. 
Fragments caused by an explosion result in greater loss of life than direct shots. Particles of a bomb case, which are shaped to form fragments, create the effect of hundreds of bullets in near area. Contrary to expectations, these fragments have more fatal effects both for soldiers and vehicles. The results of the investigations about the effects of Fragment Simulating Projectiles (FSP) on woven composites such as Celotex and GFRP targets which depends on the experimentally derived empirical function to define ballistic limit are reported by Jordan and Naito $[15,16]$.

The aim of this study is to analyze the suitability of Wen's and Jordan's model for rubberized aramid plates under .30 caliber FSP impact. Ballistic plates are tested in an accredited test laboratory in Singapore and inspections are executed by using computerized tomography (CT) scans.

\section{FAILURE MODES}

Wambua [1] defines that failure of the composite starts instantaneously at the face due to high contact stresses applied by the projectile on the front side (this encounter causes immediate matrix cracking). A compressive pulse (or transient stress wave) is induced in the materials just ahead of the projectile. Meanwhile, the stresses to the sides of the projectile are largely shear and the composite fails by shear as the projectile advances into the target. Shear cutout is usually the first stage of perforation in ballistic impact. It may, however, be the only failure mechanism at very high speed impact, where the damage does not extend far from the hole. Variable penetration velocity results from the deceleration of the projectile during penetration and this causes a change in failure modes. The initial shear cut-out of fibres is followed by fracture of the fibres by tensile forces (possibly after the projectile speed falls below the critical velocity for shear cut-out to occur), and then failure of the composite by delamination.

Wen's analytical model $[12,13]$, presenting the effect of rigid impactors with different nose shapes at varying velocities to the penetration and perforation of FRP laminates, based upon the assumption of the addition both quasi-static and dynamic deformations on the target material. Equations for ballistic limit velocity and depth of penetration have been obtained by experimental observations. In addition to Wen's model, Jordan and Naito $[15,16]$ have presented similar approach for the inspection of deformation on Celotex and GFRP laminates with different nose shaped impacters at varying velocities, providing the suitability of Wen's analytical equation with the experimental results.

For the analysis of thick targets, the wave propagation along the thickness direction needs to be considered. The wave propagation through the thickness direction causes different failure reactions inside the target depending on the contact force, mass and velocity of the impactor, which designates the impact kinetic energy. The dominant damage mechanisms of composite laminates are defined as de-lamination and fiber failure by Johnson et al [17]. Tita et al. [18] defines these failure mechanisms at two modes: (i) Intra-ply failure which damages fibers, polymeric matrix and/or interface between fibers and matrix. (ii)
Inter-ply failure mode that consists of delaminations between plies.

Sutherland and Soares [19] defined the damage mechanism of composite plates and reported that the most important variations seen were between the responses of thin and thick composites. Thin plates suffered internal delamination but did not affect the response significantly. High deflections gave a membrane stiffening effect until high incident energies back-face fiber failure led to perforation. Thick plates showed both significant shear and indentation deformation. A bi-linear force-displacement response as de-lamination leading to a significant stiffness reduction was followed by front-face initiated fiber failure causing to perforation and/or shear failure.

Abrate [20] presented a definition for predicting failure of the fibers, failure of the matrix and delamination, which are based on the composite stresses or strains. Fiber failure (Eq. $1 \mathrm{a})$, matrix cracking (Eq. $1 \mathrm{~b}$ ) and delamination (Eq. $1 \mathrm{c}$ ) failures due to the shear forces are predicted as follows;

$$
\begin{aligned}
& \left(\frac{\sigma_{11}}{X_{T}}\right)^{2}+\left(\frac{\sigma_{12}}{S_{12}}\right)^{2}+\left(\frac{\sigma_{13}}{S_{13}}\right)^{2}=1 ; \\
& \left(\frac{\sigma_{22}}{Y_{T}}\right)^{2}+\left(\frac{\sigma_{12}}{S_{12}}\right)^{2}+\left(\frac{\sigma_{23}}{S_{23}}\right)^{2}=1 ; \\
& \left(\frac{\sigma_{33}}{Z_{T}}\right)^{2}+\left(\frac{\sigma_{13}}{S_{13}}\right)^{2}+\left(\frac{\sigma_{23}}{S_{23}}\right)^{2}=1,
\end{aligned}
$$

where $S_{\mathrm{ij}}(\mathrm{i}, \mathrm{j}=1,2,3)$ represents the shear strength; $X_{\mathrm{T}}$, $Y_{\mathrm{T}}, Z_{\mathrm{T}}$ are the strength of the composite fiber and $\sigma_{\mathrm{ij}}$ $(\mathrm{i}, \mathrm{j}=1,2,3)$ are the stresses in the plane perpendicular to the material principal axis 1, 2 and 3 respectively.

Furthermore, the amount and the type of failure mechanisms activated depend on some factors: Mass, velocity and geometry of the impactor, geometry of the structure, type of fiber and/or matrix used for manufacturing of the composite plate, stacking sequence of the plies. Final damage is sensitive to even small changes in the fiber/resin type, ratio, architecture, interface and laminate production method. Therefore, it is important to realize that a laminate that performs well in one area may not perform well in another.

\section{EXPERIMENTAL SETUP}

Both the material behavior and the impact phenomenon complexity require the investigation of ballistic plates experimentally. To be able to have an understanding the damage behavior for a given material, it is vital that the target production and tests should be performed under controlled conditions, as defined international standards $[21,22]$ by means of environmental conditions and procedures, in order to prevent even rare manufacturing mistakes and environmental changes during tests.

In this study; two ballistic plates, which are named as A3-1 and A4-1, made of the same material (rubberized aramid) with dimensions of $300 \mathrm{~mm} \times 600 \mathrm{~mm} \times 15 \mathrm{~mm}$ (Beam $\times$ Length $\times$ Thickness) are used. Both identical plates were fabricated using plain weave prepregs by an international supplier to avoid manufacturing changes and 
mistakes.

Tests are performed at an internationally accredited ballistic test laboratory in Singapore under controlled environment according to Stanag 2920 [21] for .30 caliber FSP whose weight is defined as $2.84 \pm 0.03$ grams with cold rolled, annealed steel material at $30 \pm 1$ Rockwell hardness C. A view of generic setup for ballistic tests and the geometry of .30 caliber FSP is presented at Fig. 1 and Fig. 2 respectively.

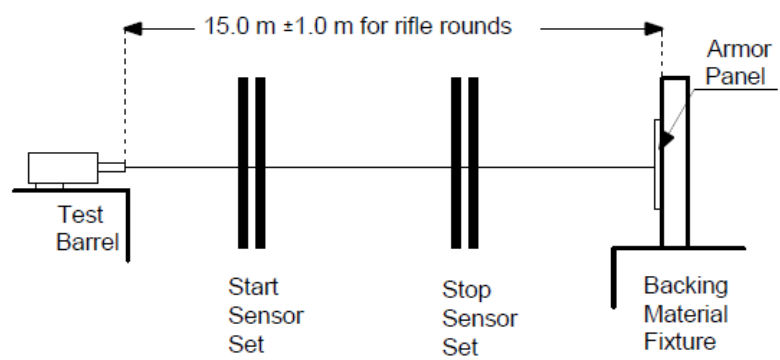

Fig. 1. A view of generic setup for ballistic tests [22]
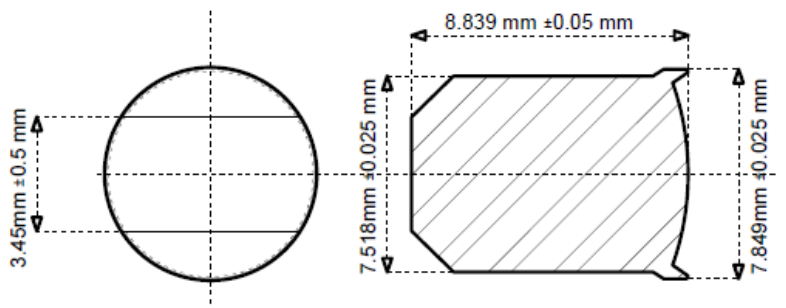

Fig. 2. .30 Caliber fragment simulator [21]

\section{EXPERIMENTAL RESULTS}

In addition to the different kinds of deformations caused by the impact, customers are particularly interested in whether the impacter stops or not. Therefore, it is obligatory to explain complete and partial penetration before examination of test results as follows as defined at [22],

- Complete Penetration (CP): The complete perforation of an armor sample or panel by a test bullet or by a fragment of the bullet or armor sample itself, as evidenced by the presence of that bullet or fragment (armor or bullet) in the backing material or by a hole which passes through the armor and/or backing material.

- Partial Penetration (PP): Any impact that is not a complete penetration is considered a partial penetration.

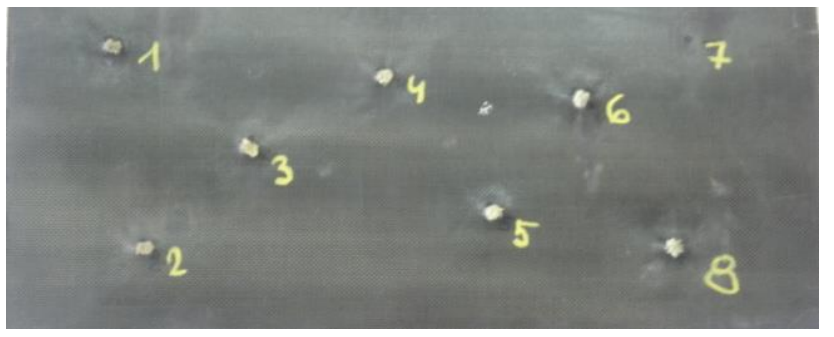

Fig. 3. Shot numbers written on the plate's strike face

Eight FSP shots were performed at the velocities between $811.0 \mathrm{~m} / \mathrm{s}$ and $950.4 \mathrm{~m} / \mathrm{s}$. Each shot number is written on the plates as presented at Fig. 3 and the velocities are listed at Table 1 according to shot numbers.

\section{INSPECTION}

How well plate resists delamination, fiber damage, perforation, plunging, bushing, crater shape and how the stiffness is affected by damage need to be considered during investigations. The plates are investigated after impacts using CT scan views at three directions: (i) Coronal Plane (axis of beam to length), (ii) Sagittal Plane (axis of length to thickness), (iii) Transverse Plane (axis of beam to thickness). These views of inspection for shot number 6 at A4-1 named sample is presented at Fig. 4 in which an artificial irradiation caused by stopped FSP is seen as a brilliant white area.

Table 1. Velocities and penetration info in accordance with the shot numbers

\begin{tabular}{|c|c|c|c|}
\hline $\begin{array}{l}\text { Target } \\
\text { name }\end{array}$ & $\begin{array}{c}\text { Shot } \\
\text { number }\end{array}$ & $\begin{array}{c}\text { FSP velocity, } \\
\mathrm{m} / \mathrm{s}\end{array}$ & Penetration \\
\hline \multirow{8}{*}{ A3-1 } & 1 & 811.0 & $\mathrm{PP}$ \\
\hline & 2 & 827.5 & PP \\
\hline & 3 & 858.5 & $\mathrm{PP}$ \\
\hline & 4 & 950.4 & $\mathrm{CP}$ \\
\hline & 5 & 918.1 & $\mathrm{CP}$ \\
\hline & 6 & 882.8 & $\mathrm{CP}$ \\
\hline & 7 & 857.5 & PP \\
\hline & 8 & 884.0 & $\mathrm{CP}$ \\
\hline \multirow{8}{*}{ A4-1 } & 1 & 898.6 & $\mathrm{CP}$ \\
\hline & 2 & 862.1 & $\mathrm{PP}$ \\
\hline & 3 & 875.5 & $\mathrm{CP}$ \\
\hline & 4 & 886.7 & $\mathrm{CP}$ \\
\hline & 5 & 851.8 & $\mathrm{PP}$ \\
\hline & 6 & 862.0 & $\mathrm{PP}$ \\
\hline & 7 & Failed & Not Fair \\
\hline & 8 & 876.0 & $\mathrm{CP}$ \\
\hline
\end{tabular}

Measurements for ballistic plates after impact are defined by Milman et al. [23] as depth of penetration $(\mathrm{H})$, the thickness of the impenetrable bottom ( $\mathrm{t})$, the drawing of the target sheet (1) and the thickness of target sheet $(\delta)$ which is presented at Fig. 5 a. In this study, deformation characteristics at impacted plate are inspected by using computerized techniques as presented at Fig. $5 \mathrm{~b}$. The distances are measured as presented at Fig. 5 c for every CT scan directions where:

- Fiber failure can be inspected by the measurements of surface crater length (a);

- Matrix failure by the crater depth (d) and

- Delamination behavior which is the most significant effect on the stiffness of the plate by delamination length (c), by bulge depth (f) and plugging depth (e).

It is obvious that more details at the measurements with accurate precision result in deeply understanding of impact resistance of the material while absorbing kinetic energy by fiber damage, delamination and perforation. Therefore, the investigation of the material resistance can be obtained consisting of all failure mechanisms. Since the deformations over the laminated composite plates have three major parts, i.e. fiber failure, matrix cracking and delamination, the main identities of fiber failure given in Eq. $1 \mathrm{a}$ and matrix cracking given in Eq. $1 \mathrm{~b}$ can be observed by Depth of Penetration (DOP) values which can be defined as the total deformation of fiber failure at the strike face and matrix cracking through the thickness resulting crater shape deformation on the surface. 


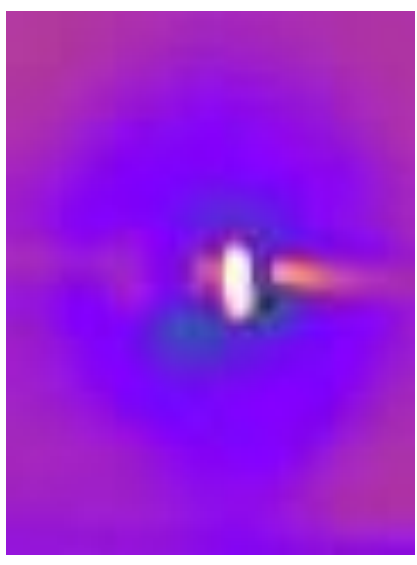

a

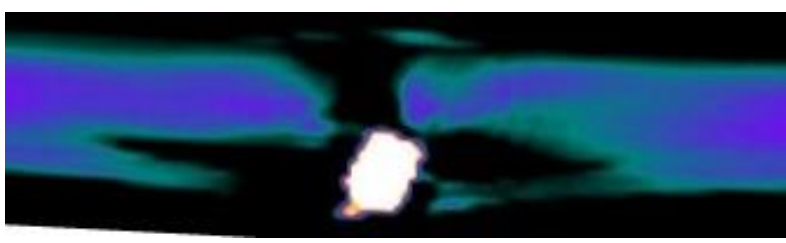

c

Fig. 4. Inspection planes: $a-$ Coronal plane; $b-$ Sagittal plane; $c-$ Transverse plane

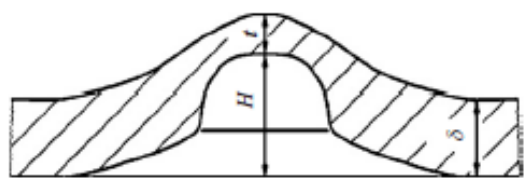

a

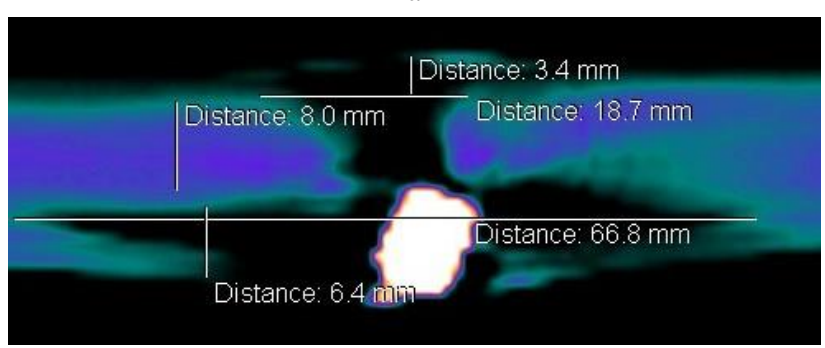

b

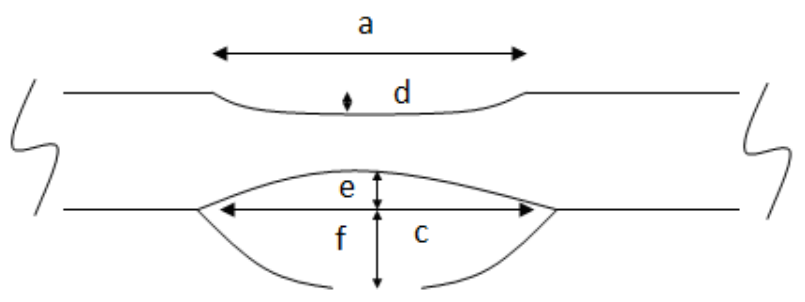

c

Fig. 5. Measurements of deformations: a - as defined by Milman et al. [23]; b-CT Scan measurements used in this study; $\mathrm{c}$-generalized measured distances for impacts at all plane views

Jordan and Naito [14] presented empirical equations which are given at Eq. 2 a for Maftex and Eq. 2 b for Celotex, to obtain $D O P$ values as a combined inspection of fiber failure at the surface and matrix cracking through the thickness of the target plate. DOP and crater shape deformations with bulge and plugging depth values can be assumed as the major parts of fiber failure and matrix cracking deformations.

$V_{s}=17.90 D O P^{0.736} m^{-0.255}$;

$V_{s}=462.5+0.370 m+1.95 D O P-61.79 m^{0.667}$,

where $V_{s}$ is strike velocity $(\mathrm{m} / \mathrm{s}) ; D O P$ is depth of penetration $(\mathrm{mm})$ and $m$ is fragment mass $(\mathrm{g})$. Since the strike velocity and the impacter mass are known for this study and DOP values can be measured precisely, suitability of the Eq. 2 a, b and the error percentages are presented at Table 2 .

Table 2. Comparison of $D O P$ values

\begin{tabular}{|c|c|c|c|c|c|}
\hline 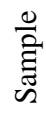 & $\begin{array}{l}\dot{0} \\
\dot{z} \\
\frac{0}{n}\end{array}$ & $\begin{array}{c}\text { Eq. } 2 \mathrm{a} \\
D O P, \mathrm{~mm}\end{array}$ & Error, \% & $\begin{array}{c}\text { Eq. } 2 \mathrm{~b} \\
D O P \\
\mathrm{~mm}\end{array}$ & Error, \% \\
\hline \multirow{8}{*}{ 完 } & 1 & 20.14 & 25.51 & 24.17 & 37.95 \\
\hline & 2 & 20.44 & 26.61 & 25.02 & 40.05 \\
\hline & 3 & 20.99 & 28.57 & 26.61 & 43.63 \\
\hline & 4 & 22.63 & 33.72 & 31.32 & 52.11 \\
\hline & 5 & 22.06 & 32.01 & 29.67 & 49.44 \\
\hline & 6 & 21.43 & 30.02 & 27.86 & 46.15 \\
\hline & 7 & 20.98 & 28.51 & 26.56 & 43.52 \\
\hline & 8 & 21.46 & 30.09 & 27.92 & 46.27 \\
\hline \multirow{8}{*}{ 安 } & 1 & 21.72 & 30.93 & 28.67 & 47.67 \\
\hline & 2 & 21.06 & 28.79 & 26.79 & 44.02 \\
\hline & 3 & 21.31 & 29.59 & 27.48 & 45.42 \\
\hline & 4 & 21.51 & 30.25 & 28.06 & 46.54 \\
\hline & 5 & 20.88 & 28.16 & 26.27 & 42.89 \\
\hline & 6 & 21.06 & 28.78 & 26.79 & 44.01 \\
\hline & 7 & -- & -- & -- & -- \\
\hline & 8 & 21.31 & 29.62 & 27.51 & 45.47 \\
\hline \multicolumn{4}{|c|}{ Average error $29.41 \%$} & \multicolumn{2}{|c|}{ Avr. error $45.01 \%$} \\
\hline
\end{tabular}

The $D O P$ can be measured just for PP impacts because its value is irrelevant at $\mathrm{CP}$ impacts where the plate completely penetrated at its own thickness. Hence the error values are calculated for the thickness of the plate which is the limit of PP impact. The sample plates used in experiments have $15 \mathrm{~mm}$. thicknesses which limit maximum $D O P$ at this measure. Error percentages are presented as a result of Jordan's model for Maftex and Celotex plates which are depending on the Wen's approximation model, to measure the applicability of damage models on rubberized aramid plates. Nevertheless the $D O P$ values achieved by Maftex model have approximately $30 \%$ deviation as well as Celotex damage model causes $45 \%$ deviation. While these two damage models are not suitable for the prediction of rubberized aramid penetration strength, it is mandatory developing a new and suitable DOP prediction model.

\section{PREDICTIVE EQUATION DEVELOPMENT AND VALIDATION}

Since the minimal average error is approximately $30 \%$ for the current material, it is irrational to use the prediction formulas mentioned above for rubberized aramid plates. It is obvious that developing a prediction equation for rubberized aramid armor plates resisting .30 caliber FSP is essential.

Inspection of the experimental data according to impact velocities is plotted at Fig. 6 in which the changes 
of deformation parameters are presented. Changes in delamination length are prominently observed since its effect is more obvious on the stiffness of the plate.

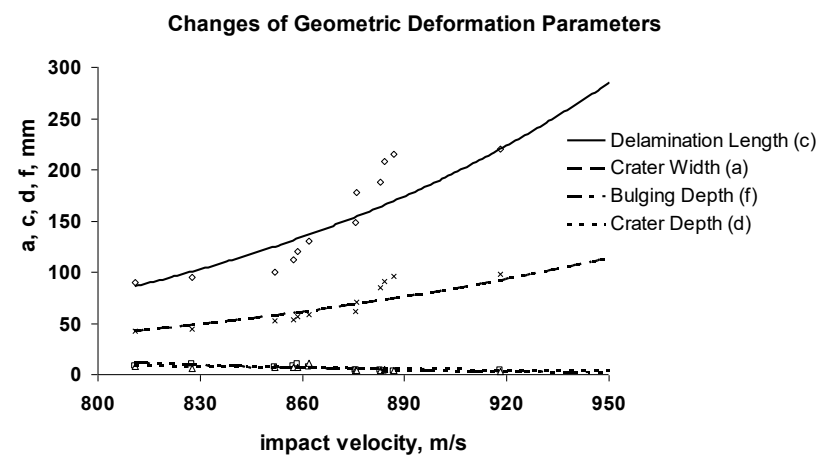

Fig. 6. Changes of geometric deformation parameters according to impact velocity

An empirical equation for the ballistic limit velocity is developed using the least squares regression analysis as presented in Eq. 3.

$V_{B L}=775.57+7.85 t-14.83 m^{2 / 3}$,

where $t$ is the thickness of the target plate and $m$ is the mass of the impacter. The coefficient of determination $\left(R^{2}\right)$ equals 0.79 indicating that the regression equation is a moderate fit. Nevertheless, the equation is validated using test reports and error percentage between observed value and calculated ballistic limit value developed in this study as presented at Table 3 .

As can be seen at Table 3, the $V_{\mathrm{BL}}$ values of the plates as reported by the testing facility are performed with an error of less than $1 \%$. Eq. 3 calculates the same $V_{\mathrm{BL}}$ value since the thicknesses of the plates are identical and the tests are performed with the same FSP.

Table 3. Comparison of ballistic limit velocity

\begin{tabular}{|c|c|c|c|}
\hline $\begin{array}{c}\text { Target } \\
\text { name }\end{array}$ & $\begin{array}{c}\text { Reported } V_{\mathrm{BL}}, \\
\mathrm{m} / \mathrm{s}\end{array}$ & Eq. 3 & Error, \% \\
\hline $\mathrm{A} 3-1$ & 871.1 & 863.58 & 0.85 \\
\hline $\mathrm{A} 4-1$ & 869.0 & 863.58 & 0.62 \\
\hline
\end{tabular}

\section{CONCLUSION}

An inspection of rubberized aramid ballistic plates is performed according to test reports for .30 caliber FSP impact. The experimental data is used to develop an empirical equation for calculating ballistic limit velocity of the plates.

Due to the experiments achieved to provide the ballistic limit value of sample plates, the impact velocities were chosen close to each other which make the results suitable for an empirical study. The behavior of the plate is inspected according to damage mechanisms of composite materials which are defined at the manuscript and results are compared with Wen's and Jordan's damage models. Comparison results indicate the inappropriateness of these models owing to the fact that composite materials can have different mechanical properties even if they have similar component phases. In addition, having design flexibility which is essentially exploiting the possibility of obtaining optimum design through a combination of structural / material concepts, stacking sequence, ply orientation, choice of the component phases, etc. causes these materials to be worthy for investigations. However changing combinations require detailed experiments and investigations to have a better understanding of this futuristic material kind.

Since the most obvious damage occurred in delamination failure mode which causes decrease in the stiffness, the inspection was performed for both delamination of the plate and fiber failure at near impact velocities. The delamination behavior of the material was observed through the impact velocities and perforation occurred after the length of delamination passed ten times of plate thickness.

Empirical equation is developed using least square method for the effect of this parameter consisting of thickness of target plate and impacter mass. The validation study is performed by using real test results reported by an international accredited test laboratory. An accurate and rapid ballistic limit velocity determination technique is presented and recommended for field and laboratory applications.

\section{REFERENCES}

1. Wambua, P., Vangrimde, B., Lomov, S., Verpoest, I. The Response of Natural Fiber Composites to Ballistic Impact by Fragment Simulating Projectiles Composite Structures 77 2007: pp. $232-240$.

2. Swanson, S. R. Introduction to Design and Analysis with Advanced Composite Materials. Prentice Hall Inc., NJ, 1997: pp. 19-27.

3. Naik, N. K., Shirao, P., Reddy, B. C. K. Ballistic Impact Behaviour of Woven Fabric Composites: Parametric Studies Materials Science and Engineering A 412 2005: pp. $104-116$. http://dx.doi.org/10.1016/j.msea.2005.08.019

4. Mamivand, M., Liaghat, G.H. A Model for Ballistic Impact on Multi-Layer Fabric Targets International Journal of Impact Engineering 37 2010: pp. 806-812. http://dx.doi.org/10.1016/j.ijimpeng.2010.01.003

5. Hetherington, J.G. Energy and Momentum Changes During Ballistic Perforation International Journal of Impact Engineering 18 (3) 1995: pp. 319-337.

6. Corbett, G.G., Reid, S.R., Johnson, W. Impact Loading of Plates And Shells By Free-Flying Projectiles: A Review International Journal of Impact Engineering 18 (2) 1996: pp. $141-230$. http://dx.doi.org/10.1016/0734-743X(95)00023-4

7. Goldsmith, W. Non-ideal Projectile Impact On Targets International Journal of Impact Engineering 22 1999: pp. $95-395$. http://dx.doi.org/10.1016/S0734-743X(98)00031-1

8. Ben-Dor, G., Dubinsky, A., Elperin, T. Applied HighSpeed Plate Penetration Dynamics. Springer, Netherlands, 2006: pp. $142-151$

9. Ben-Dor, G., Dubinsky, A., Elperin, T. Ballistic impact:Recent Advances in Analytical Modeling of Plate Penetration Dynamics: A Review Applied Mechanics Reviews 58 2005: pp. 355-370. http://dx.doi.org/10.1115/1.2048626

10. Abrate, S. Impact on Composite Structures. Cambridge University Press, Cambridge, 1998: pp. 151-158. http://dx.doi.org/10.1017/CBO9780511574504 
11. Reid, S.R., Zhou, G. Impact Behaviour of Fibre-Reinforced Composite Materials and Structures. Woodhead Publishing Ltd., CRC Press,USA, 2000:pp.187-204.

12. Wen, H. M. Predicting The Penetration And Perforation of FRP Laminates Struck Normally By Projectiles With Different Nose Shapes Composite Structures 49 2000: pp. $321-329$. http://dx.doi.org/10.1016/S0263-8223(00)00064-7

13. Wen, H. M. Penetration And Perforation of Thick FRP Laminates Composite Science and Technology 61 2001: pp. $1163-1172$. http://dx.doi.org/10.1016/S0266-3538(01)00020-3

14. Ansar, M., Xinwei, W., Chouwei, Z. Modeling Strategies of 3D Woven Composites: A review Composite Structures 93 2011: pp. $1947-1963$. http://dx.doi.org/10.1016/j.compstruct.2011.03.010

15. Jordan, J.B., Naito, C.J. Calculating Fragment Impact Velocity from Penetration Data International Journal of Impact Engineering 37 2010: pp. 530-536.

16. Jordan, J.B., Naito, C.J. An Experimental Investigation of The Effect Of Nose Shape on Fragments Penetrating GFRP International Journal of Impact Engineering 63 2014: pp. $63-71$. http://dx.doi.org/10.1016/j.ijimpeng.2013.08.002

17. Johnson, H.E., Louca, L.A., Mouring, S., Fallah, A.S. Modelling Impact Damage In Marine Composite Panels International Journal of Impact Engineering 36 2009: pp. $25-39$.

http://dx.doi.org/10.1016/j.ijimpeng.2008.01.013
18. Tita, V., Carvalho, J., Vandepitte, D. Failure Analysis of Low Velocity Impact On Thin Composite Laminates: Experimental and Numerical Approaches Composite Structures 83 2008: pp. 413-428. http://dx.doi.org/10.1016/j.compstruct.2007.06.003

19. Sutherland, L.S., Soares, C.G. Impact Behaviour of Typical Marine Composite Laminates Composites: Part B 37 2006: pp. 89-100. http://dx.doi.org/10.1016/j.compositesb.2005.09.001

20. Abrate, S. Impact Engineering of Composite Structures, International Center for Mechanical Sciences, Courses and Lectures No:526, Springer Wien New York, 2011: pp. $18-23$. http://dx.doi.org/10.1007/978-3-7091-0523-8

21. STANAG 2920, Ed.2, Ballistic Test Method for Personal Armour Materials and Combat Clothing, NSA Standardization Agreement, Unclassified, 2003.

22. Mukasey, M.B., Sedgwick, J.L., Hagy, D.W. Ballistic Resistance of Body Armor, NIJ Standard-0101.06, US Department of Justice, 2008: pp. 21.

23. Milman, Y.V., Chugunova, S.I., Goncharova, I.V., Goncharuk, V.A., Yefimov, N.A. Physics of deformation and fracture at impact loading and penetration International Journal of Impact Engineering 33 2006: pp. 452-462. http://dx.doi.org/10.1016/j.ijimpeng.2006.09.058 